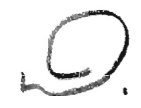

\title{
$321398(81)$
}

\section{A Faculdade de Direito e a situação nacional.}

No decurso do mês de agôsto de 1962, tendo em vista as continuas ameaças e maquinações contra a ordem jurídica constituída, a quase totalidade dos professôres, catedráticos e livres docentes, da Faculdade de Direito da usP deliberou dirigir um manifesto à Nação, sôbre cuja ressonância dão eloqüente testemunho os documentos que a seguir se publicam.

\section{Proclamação da Faculdade de Direito.}

"Os professôres da Faculdade de Direito da Universidade de São Paulo, fiéis à sua tradição de constante e intemerata salvaguarda dos princípios da legalidade democrática, sentem-se no dever de tornar públicos a sua apreensão e o seu protesto em face das reiteradas violações da Constituição e das leis por parte daqueles que têm em vista o desprestígio das instituições vigentes, para obter, através de múltiplas manifestações de fôrça, resultados que só seriam legítimos se obedecidas as normas que disciplinam o exercício dos poderes da República.

Os que esta subscrevem não são todos adeptos do parlamentarismo, mas todos condenam, sem discrepância, quaisquer processos tendentes a subtrair ao Congresso Nacional a competência que a ordem constitucional lhe confere para realizar as reformas que mais convenham à Nação, graças ao livre pronunciamento dos partidos políticos que representam a opinião pública do País.

Não ignoram os mestres desta Casa, mas antes reconhecem e proclamam a necessidade de revisões em nossa estru- 
tura econômica, social e jurídico-política, mas, quanto mais graves e urgentes os problemas a resolver em benefício do povo, maior deve ser a garantia reconhecida aos processos democráticos do govêrno e mais prudente a ação do Estado, o que só pode ser obtido pela fidelidade à Constituicão, sem a qual não há planos e programas que vinguem nas Nações que amam e praticam a liberdade.

No entanto, campeia, em todos os setores e camadas sociais, a propaganda de elementos subversivos e anti-democráticos, os quais se aproveitam da omissão, quando não da conivência dos responsáveis pela ordem pública.

Entidades sindicais, dignas de todo aprêço e louvor no âmbito das respectivas competências, arvoram-se em mentores do destino do País, lançando mão de greves políticas, altamente prejudiciais aos interêsses das massas obreiras, com o intuito ilícito de impor programas de govêrno e nomes de ministros; organismos estudantis, convertidos em instrumentos de subversão das hierarquias universitárias, provocam a deserção dos bancos acadêmicos, dominados por uma minoria ativista que mal disfarça os seus desígnios revolucionários; e, enquanto tal acontece, os órgãos estatais se omitem, tomados de pânico, como se fôssem desconsoladas testemunhas da dissolução progressiva do princípio de autoridade.

Felizmente, é do seio das próprias classes trabalhadoras, e é de grêmios de ginasianos e universitários que brota a reação salutar contra a desordem, como um toque de alerta e de chamado a todos os homens responsáveis do País, a fim de que não sejam postergadas as tradições cristãs de nossa formação histórica, nem violentada a consciência cívica do povo brasileiro, cuja maturidade política se quer afrontar através de pronunciamentos anacrônicos e intempestivos.

A prova cabal do caráter revolucionário do movimento desencadeado no âmbito universitário têmo-la na circunstância deveras impressionante de ter-se recorrido à greve logo no início do ano letivo, quando as Universidades se 
aprestavam a adaptar-se aos preceitos da nova lei de diretrizes e bases, que veio possibilitar maior autonomia aos institutos de ensino superior. Obedecendo a um plano adrede preparado, levantou-se a bandeira da representação de um têrço do corpo discente nos órgãos dirigentes da Universidade sem se invocar um só exemplo salutar de grande Nação, do mundo ocidental ou do campo totalitário, que admita tal inovação subversiva na estrutura de entidades que devem ser norteadas tão sòmente pelos valores da inteligência e da cultura, do preparo metódico e da pesquisa científica, a salvo de arremetidas demagógicas, da inexperiência ou da improvisação.

Ao mesmo tempo, em nossa Faculdade, invocando a nulidade de um concurso, matéria ainda pendente do julgamento dos órgãos próprios da Universidade, de acôrdo com os ditames da lei, o Centro Acadêmico XI de Agôsto, que devia ser o primeiro a respeitar o direito constituído, deflagra uma greve sem sentido, cujo último episódio é a ocupação pela violência das Arcadas, bastião no passado das mais nobres campanhas cívicas, hoje ameaçadas de se converterem em valhacouto de agitadores.

Estão certos os professôres de que a grande maioria dos estudantes não comunga com os planos de subversão que se ocultam nas dobras das mais edificantes reivindicaçốes culturais ou políticas, mas, ontem como hoje, é tão condenável quem pactua com a desordem nas assembléias, como quem delas deserta por comodismo ou cálculo, aliando o ócio fácil à fuga às atitudes francas e corajosas.

É diante dêsse quadro de intranqüilidade e violência que agita e conturba a Nação, quando o que mais se arrisca de perder é o senso dos valores morais, que nós, professôres do mais antigo instituto de ensino jurídico do País, medindo todo o pêso de nossas responsabilidades perante a história, consideramos necessário unir o nosso brado ao daqueles que já se dispuzeram a mostrar à pátria que nada há mais melancólico do que uma maioria privada da consciência de 
sua fôrça, nem nada mais vil do que o silêncio no instante em que é mistér decidir entre a liberdade e a opressão, para sermos dignos da tradição democrática do povo brasileiro.

São Paulo, 9 de agôsto de 1962.

Luís Antônio da Gama e Silva

J. J. Cardoso de Melo Neto

Waldemar Martins Ferreira

Alvino Ferreira Lima

Vicente Ráo

Antônio Ferreira de Almeida Júnior

Ernesto de Moraes Leme

Honório Fernandes Monteiro

Noé Azevedo

José Soares de Melo

Basileu Garcia

José Carlos de Ataliba Nogueira

Miguel Reale (relator)

Theotônio Monteiro de Barros Filho

Luís Eulálio de Bueno Vidigal

José Pinto Antunes

Sílvio Marcondes Machado

Alfredo Buzaid

Moacir Amaral Santos

Washington de Barros Monteiro

Nicolau Nazo

João de Deus Cardoso de Melo

José Antônio de Almeida Amazonas

Esther de Figueiredo Ferraz

José Loureiro Júnior

Alexandre Augusto de Castro Correia

Antônio Chaves

Luís Araújo Correa de Brito

Vicente Marotta Rangel

Sílvio Rodrigues 
Oscar Barreto Filho

Fernando Henrique Mendes de Almeida

Celso Neves

Luis Ambra

Guilherme Percival de Oliveira

João Batista de Oliveira e Costa Júnior

Paulo Carneiro Maia

Oto de Sousa Lima

José Luis de Anhaia Melo

Geraldo de Ulhôa Cintra.

\section{Repercussão e apoio dos antigos alunos da Faculdade} ao manifesto dos professôres.

A proclamação supra logrou a mais alta repercussão tanto em São Paulo como nos demais Estados da Federação. Logo no dia 11 de agôsto, durante o almôço de confraternização, o Diretor da Faculdade recebeu o seguinte documento:

"Nós, antigos alunos da Faculdade de Direito de São Paulo, ao ensejo das comemorações da Fundação dos Cursos Jurídicos, no Brasil, queremos consignar o nosso irrestrito apoio e o mais vivo aplauso ao manifesto dos professôres da Academia do Largo de São Francisco, cujos têrmos bem traduzem os sentimentos de todos os que mantêm vivas as tradições de civismo e de cultura da nossa Escola e o pensamento dos verdadeiros democratas brasileiros. São Paulo, 11 de agôsto de 1962. (aa) - Pedro Chaves, Luís Pinto Serva, Theodolindo Castiglione, Osvaldo Pinto do Amaral, João de Azevedo Carneiro Maia, J. B. de Arruda Sampaio, Leoncio Ribas Marinho, Cid B. de Castro Prado, Lucio Cintra do Prado, Jayro Franco, Boanerges do Amaral Gurgel, A. Padua Nunes, Gaspar E. Passos, Cassio Egydio de Queiroz Aranha, Ruy Pinho, Luiz de Azevedo Castro. Oscar de Andrade Coelho, Paulo de Mesquita, José M. de Alencar, Oreste Bianco Dicessa, Octavio de Barros, N. Pinto e Silva, José V. Bueno, José J. Legaspe, José Roberto Lima. Tulio Martins, 
Paulo Mendes, J. C. R. Geribello, Acacio Rezende, Vergniaud Elyseu, Romeu Orio, Antonio Cardoso, A. Godoy, Plínio de Mello, Cyro Christiano de Souza, Joviro Gonçalves Foz, Roberto Maldonado Loureiro, Francisco Lobo Filho, Ubirajara Martins, Breno de Toledo Leite, Heladio Capote Valente, Emilio Ippolito, A. C. de Camargo Viana, João Leonel Meira, A. S. Castilho Pereira, Azevedo Pinheiro, A. Mercado Junior, Francisco de Barros Pinheiro, João de Vasconcelos, Laerte Fleury de Oliveira, Otavio Uchoa da Veiga, João Bernardes da Silva, Roberto Victor Cordeiro, Renato Taglianetti, Sylvio Novais, Raul Leme Monteiro, Gabriel de Almeida Gatti, Luiz Carlos Galvão Coelho, Gerson de Oliveira, Oscar Barbosa Filho, Lotello Giannelli, Cassio Ribeiro da Silva, Jorge Feldmann, Caio de Lima Correa, Gilberto Barcellos, Eubis Amaral, Clóvis Costa Correia da Silva, Marigildo de Camargo Braga, Jorge B. Hirs, Miguel de Araújo, Luciano Ferreira Leite, José Eduardo Ferraz Monaco, Vieira Neto, Roge de Carvalho Monge, Ruy Sodré, Sebastião Carneiro Giraldes, Laurindo Minhoto, Felizardo Calil, João Gualberto de Oliveira, Alcyr de Toledo Leite, José Eduardo Bento Vidal, Paulo P. de Faria e Silva, Moacyr Cunha Fonseca, Carlos Casimiro Costa, Celso Dias de Moura, C. B. Livramento, Antonio Marzagão Barbuto, Octavio Augusto Machado de Barros, Valencio de Barros, Carlos Galvão Vicente de Azevedo, Raphael Carneiro Maia, Afonso Gutierrez, Miguel Ferreira da Silva Netto, Valentim Alves da Silva, Antonio Fonseca Rosa, Luiz Swartman, Péricles Rolim, Antonio Tupinambá Vampré, Gastão de Campos Mello, Marcelo Pais Barreto, A. Pavan de Souza Marques, Maria Aparecida de A. P. Galvão, Luiz Cassio dos Santos Werneck, Ricardo Barros, Vicente de Oliveira Andrade, Armando Marcondes Machado Junior, Paulo Godoy Moreira, Aloysio G. Martins, Marina Reis de Oliveira, Hugo Muniz, Edy de Campos Silveira, João Leal de Rezende, Cícero Sampaio, Licínio Silva Filho, Paulo Valle Nogueira, Ruy Cardoso de Melo Tucunduva, Alfredo Gomes, Leon Frejda Szklarowsky, além de centenas de outras assinaturas. 


\section{Carta do ex-presidente Altino Arantes.}

Especial destaque merece a carta que o Professor Gama e Silva recebeu do Dr. Altino Arantes ex-presidente do Estado de São Paulo, redigida nos seguintes têrmos:

"A Vossa Excelência e, por seu alto e benévolo intermédio, à ilustre e douta Congregação dessa querida Casa, onde aprendi a cultivar o Direito e a respeitar a Lei, peço venia para apresentar minhas sinceras congratulações pelo oportuno manifesto, no qual tão brilhante quanto corajosa e patriòticamente se pronunciaram sôbre os acontecimentos que neste grave momento ensobram os horizontes sociais e políticos da nossa Pátria. Atenciosas saudações. as.) Altino Arantes"

\section{Manifestação de outros grupos sociais.}

De outras camadas e círculos sociais, partiram manifestações de aplauso à corajosa atitude dos Mestres desta Casa, tendo a imprensa dado a notícia da seguinte proclamação subscrita por inúmeros professôres universitários, estudantes, agricultores, operários e demais classes sociais.

"Não há quem, de boa fé, não sinta ou não reconheça que a Democracia brasileira está em perigo, tais e tantas têm sido as violações perpetradas contra a Constituição e as leis, como ainda foi recentemente proclamado pela gloriosa Faculdade de Direito da Universidade de São Paulo, no manifesto com que denunciou à Nação os planos de subversão da ordem democrática, mediante crises artificiais sucessivas, promovidas pelos que pretendem solapar as bases das instituições vigentes.

"Efetivamente é esta a hora das definições francas e corajosas, afim de que o sentimento real e autêntico do País se revele e se positive, desmascarando-se a imagem postiça fabricada por uma minoria ousada, que quer nos desviar 
de nossa vocação histórica de amor à liberdade e de fidelidade aos valores da civilização cristã.

"É deveras impressionante que, às vésperas de eleições gerais, na iminência da convocação do eleitorado para o seu pronunciamento soberano, se queira obter, através de tôdas as formas de compressão, soluções forjadas de afogadilho, sob o signo da improvisação, a pretexto de salvação pública, quando as reformas fundamentais devem merecer o estudo sereno e cuidadoso da Câmara dos Deputados e do Senado, que não podem abdicar de suas competências e prerrogativas constitucionais.

"Não vamos indagar aqui da conveniência ou não dos projetos de lei delegada, apresentados em profusão pelo atual Conselho de Ministros, alguns versando matéria da mais alta relevância e gravidade, porque o que desde logo sobreleva é a verificação de que se está querendo converter a exceção em regra, tal a avalanche das proposições, o que demonstra que o que se quer é menos realizar reformas, insuscetíveis de serem efetivadas por um Gabinete de transição, - do que confundir a opinião pública e fortalecer os poderes governamentais, armando-os para não confessados desígnios.

"Não é por falta de leis que perece a Nação, mas por falta de estadistas que honestamente cumpram e façam cumprir as já existentes, sem converterem as chamadas "reformas de base" em massa de manobra para a satisfação de ambições ou de ressentimentos pessoais, de que se valem extremistas da esquerda e da direita para insuflar as suas doutrinas deletérias.

"Para os comuno-nacionalistas, em verdade, asseguram-se tôdas as liberdades, entre os aplausos e com a conivência de inocentes úteis de todos os matizes, inclusive de capitalistas que se iludem pensando poder tirar proveito de alianças espúrias com declarados adversários da iniciativa privada e da livre emprêsa, ao passo que numa discriminação odiosa, nega-se até a Governadores o direito de usar do rádio e da televisão, como se a pessoa jurídica do 
Estado se confundisse com as dos detentores do Poder Executivo Federal.

“Os signatários dêste documento não se reunem, pois, visando a qualquer interêsse político partidário, nem à defesa de quaisquer interêsses privados, mas com o fito exclusivo de alertar a Nação para a gravidade da hora presente, gravidade esta que atingiu o seu limite crítico, já ameaçando comprometer a unidade nacional, violentando a nossa consciência cristã e democrática, tentando reduzir o Brasil a um campo estagnado, onde só poderão medrar os germes da dissolução e do totalitarismo facista ou comunista, inteiramente contrários à nossa índole e às legítimas aspirações de nossa gente.

"É com grande pesar que vimos observando a fabricação de crises contínuas em todos os planos da vida brasileira - crise moral, crise na ordem política, crise na ordem social, crise na ordem econômica, crise de desesperança, gravíssima crise educacional que compromete o futuro da pátria, crise de confiança e de autoridade, do que tudo resultará a transformação de nosso país em um ajuntamento de homens sem destino e sem fé.

"Não é preciso entrarmos na análise detalhada da ingerência de elementos destruidores onde quer que surja um valor espiritual ou uma criação da autêntica civilização brasileira, mas não podemos assistir imperturbáveis à tenebrosa revolução que, sob a aparência de justiça econômica e social, se vem processando intensamente, com o intuito de fazer ruir tudo o que foi laboriosamente construído em pról da dinamização de nosso verdadeiro desenvolvimento.

"A serem consumados tais desígnios, que infelizmente somos obrigados a denunciar como partindo de elementos infiltrados nas altas esferas governamentais, chegaremos entre outros males a êstes que podem ser incluídos entre os de efeitos mais catastróficos - a perda de estímulo para a produção e o desemprêgo em massa.

"Num país de crescimento demográfico explosivo, e de uma ascenção social que ninguém ousará negar, o que se 
está verificando é a paralização de tôdas as iniciativas capazes de aumentar a renda nacional e de dar trabalho acêrca de um milhão de brasileiros que anualmente se apresentam à procura de emprêgo.

"Enquanto isso, generaliza-se o debate dos grandes temas político-constitucionais sem a sua devida elucidação e, a bem dizer, muitos dos que dêle participam não sabem - ou não querem saber - o seu real significado e a extensão de seu conteúdo. O plebiscito, por exemplo, tão insistentemente reclamado, através de declarações inoportunas ou mediante projetos de lei que atentam manifestamente contra o texto constitucional, é bem um exemplo dessa política de envolvimento malicioso da opinião pública para fins eleitorais ou subversivos, que uns e outros se conjugam no processo revolucionário em marcha.

"A politização do povo brasileiro não se aperfeiçoa no tumulto gerado pelos mais desencontrados temas, mas só poderá ser o fruto de uma serena tomada de consciência de nossos problemas, quando as idéias passarem a valer por si mesmas e não apenas como instrumento de fins dolosamente encobertos.

"Em vez do diálogo ou do debate, o que há é a algazarra. Em vez da administração, é a paralização. Em vez do trabalho fecundo de organização, é o esfôrço para impedí-la. O primeiro dever dos governos é governar com firmesa e prudência, assim como o principal direito do povo é o de dispor dos meios capazes de assegurar sua preparação para o uso consciente da liberdade com responsabilidade. A educação, porém, vem sendo substituída pela agitação. A informação pela propaganda, como se fôssemos uma Nação entregue impunemente à desordem.

"Não podemos nos deixar dominar por uma falsa prudência. Esta é uma virtude que obriga a ter coragem para afirmar e para resistir. Os responsáveis pela segurança nacional e pela ordem interna não podem defender a institucionalização da desordem. O comunismo não pode vir 
pela violência mas também não pode vir pela insídia, esta ainda mais temivel do que aquela.

"A Democracia está ganhando no mundo a guerra fria que o comunismo lhe impôs. Um pouco mais de resistência e de esfôrço, e os povos dominados pelos governos totalitários começarão a exigir, êles próprios, a perdida liberdade. A causa da paz e da liberdade no mundo depende de contermos, em cada nação ameaçada, a expansão do comunismo. Da sorte do Brasil depende a de tôda a América Latina. Desta, o destino da liberdade e da paz no mundo. A defesa do Brasil contra o inimigo interno que o corrói, depende de nós. Dos homens fraternalmente unidos em tôrno da mesma bandeira e do mesmo ideal, qualquer que seja a sua condição, quaisquer que tenham sido as suas divergências.

"Não nos esqueçamos de que o Brasil, dentre tôdas as Nações latino-americanas, é a que, por sua formação histórica e pelo grau de sua evolução econômico-social, é a que reune as condições mais propícias para romper, dentro do respeito à ordem democrática, a barreira do sub-desenvolvimento, desde que não nos deixemos dominar pelas ondas da demagogia que pretendem aniqüilar as posições já por nós conquistadas com tanta perseverança e sacrifício, impondo-nos a progressiva burocratização dos serviços e das consciências.

"Que se façam as reformas reclamadas pelo povo, mas através do livre e sereno debate das idéias, sem planos precipitados e preconcebidos, sem gestos impensados ditados pelo ódio ou pela frustação, pelo desejo incontido de mando ou pela ambição que cega até ao ponto de não deixar ver o criminoso emprêgo que dela estão sabendo fazer os que se ocultam para melhor dirigir os acontecimentos.

"É a razão pela qual conclamamos a todos os brasileiros, de tôdas as categorias sociais, para que façam ouvir a sua voz e alertem os responsáveis pelo destino da República, no sentido da preservação da ordem constituída e da defesa permanente e desassombrada dos valores morais, que constituem o patrimônio inalienável de nossa terra e de nossa gente". 